\title{
Myelomeningocele defect reconstruction with keystone flaps: vascular rationale for the design and operative technique
}

\author{
Beatriz Hatsue Kushida-Contreras ${ }^{1}$, Miguel Angel Gaxiola-García ${ }^{2}$ \\ ${ }^{1}$ Department of Plastic and Reconstructive Surgery, Hospital General de México (Mexico's General Hospital), Mexico City; ${ }^{2}$ Department of \\ Plastic and Reconstructive Surgery, Hospital Infantil de México (Mexico's Children's Hospital), Mexico City, Mexico
}

\begin{abstract}
Background Myelomeningocele is a frequently seen condition at tertiary care hospitals. Its treatment involves a variety of plastic reconstructive techniques. Herein, we present a series of myelomeningocele patients treated using keystone flaps.

Methods We gathered information regarding soft tissue reconstruction and the use of bilateral keystone flaps to treat myelomeningocele patients. We obtained data from clinical records and recorded the demographic characteristics of mothers and children with the condition. The size, level of defect, and complications detected during the follow-up were analyzed. Results A series of seven patients who underwent bilateral keystone flaps for myelomeningocele closure was analyzed. There were no cases of midline or major dehiscence, flap loss, necrosis, surgical site infections, or cerebrospinal fluid leakage. No revision procedures were performed. Minor complications included one case with minimal seroma and three cases with areas of peripheral dehiscence that healed easily using conventional measures.

Conclusions The use of keystone flaps is an adequate option for closure of dorsal midline soft tissue defects related to myelomeningocele. This technique offers predictable results with an acceptable spectrum of complications. Robust blood flow can be predicted based upon anatomical knowledge.
\end{abstract}

Keywords Surgery, plastic / Spinal dysraphism / Meningomyelocele / Surgical flaps

\author{
Correspondence: \\ Miguel Angel Gaxiola-Garcia \\ Department of Plastic and \\ Reconstructive Surgery, Hospital \\ Infantil de México Federico Gómez \\ (Mexico's Children's Hospital), Calle \\ Doctor Márquez Número 162, Colonia \\ Doctores, Mexico City 06720, Mexico \\ Tel: +52-55-5228-9917 \\ E-mail:drgaxiola@gmail.com
}

\section{INTRODUCTION}

The spina bifida spectrum encompasses defects (dysraphias) in the posterior midline that can affect the skin as well as the spinal column and its contents. Myelomeningocele is a specific type of spina bifida in which nerve roots, the meninges, and the medulla protrude [1].

The incidence of this congenital defect varies among coun- tries. It has been estimated that there are $0.5-0.8$ cases per 1,000 births in the United States and most of Europe, while in some parts of Asia the incidence is 20 times greater [2].

Low or delayed folic acid intake is a recognized risk factor for spina bifida [3]. Other maternal and environmental factors related to neural tube defects range from alcohol or substance abuse to extreme body temperature variations [2].

Early treatment has been advocated as the best course of ac-

Copyright $\odot 2021$ The Korean Society of Plastic and Reconstructive Surgeons

This is an Open Access article distributed under the terms of the Creative Commons Attribution Non-Commercial License (https://creativecommons.org/

licenses/by-nc/4.0/) which permits unrestricted non-commercial use, distribution, and reproduction in any medium, provided the original work is properly cited. I www.e-aps.org 
tion to achieve positive results and to reduce the disability rate [4], with prenatal treatment of this condition showing even better results $[5]$.

When repairing spina bifida, skin approximation must be achieved in addition to neural tube and meningeal closure. Diverse techniques have been attempted to achieve this, from skin grafts to flaps of varied designs [6]. Ideally, the skin closure must be tension-free, enduring, sensate, and have adequate blood flow. The specific location of the defect and its size inform the decision regarding the treatment method [7], since smaller defects can be treated with simpler techniques.

The anatomy of the region has been studied in the context of bilateral bipedicled paramedian fasciocutaneous flaps. These flaps depend on three main vascular territories: the parascapular and scapular branches of the circumflex scapular artery superiorly, muscular perforators, and cutaneous branches of the intercostal arteries in the middle third and extensions of the superficial circumflex iliac arcade in the lower part of the flap [8]. In paramedian flaps, the vascular pattern described is obvious considering that the skin and fascia are completely separated from the donor bed, with the blood supply entering inferiorly and superiorly as in any bipedicled flap. This is not the case for the keystone flap, in which perforators are centrally preserved via blunt undermining while the cutaneous branches of the aforementioned systems are cut during flap design. Concerning the blood flow of a keystone flap in the back, a study on the vascular anatomy of the lumbar soft tissues has shown that perforators arise from all eight lumbar arteries [9]. Proximal to the defect, the presence of constant perforators from the dorsal intercostal arteries in the middle third of the dorsum has been demonstrated [10].

Therefore, the keystone flap can be undertaken as a multi-perforator advancement flap in accordance with the perforasome theory, according to which the ability of a single perforator to sustain a large volume of soft tissue can be further expanded to enhance the flow and reliability of multiple perforators harvested at once [11]. Based on this concept, the amount of the flap that remains centrally attached to its bed before mobilization can be reduced to $10 \%$ without affecting perfusion (Fig. 1) [12].

A further anatomical consideration concerning design and flap mobilization is the superficial fascia of the trunk, which is considered to be a continuation of the ventral abdominal wall fascia. This tissue moves along with the skin when moving the flaps to the midline [8].

\section{METHODS}

We analyzed seven cases of soft tissue closure in neonatal patients with myelomeningocele. Coverage was done using fascio-

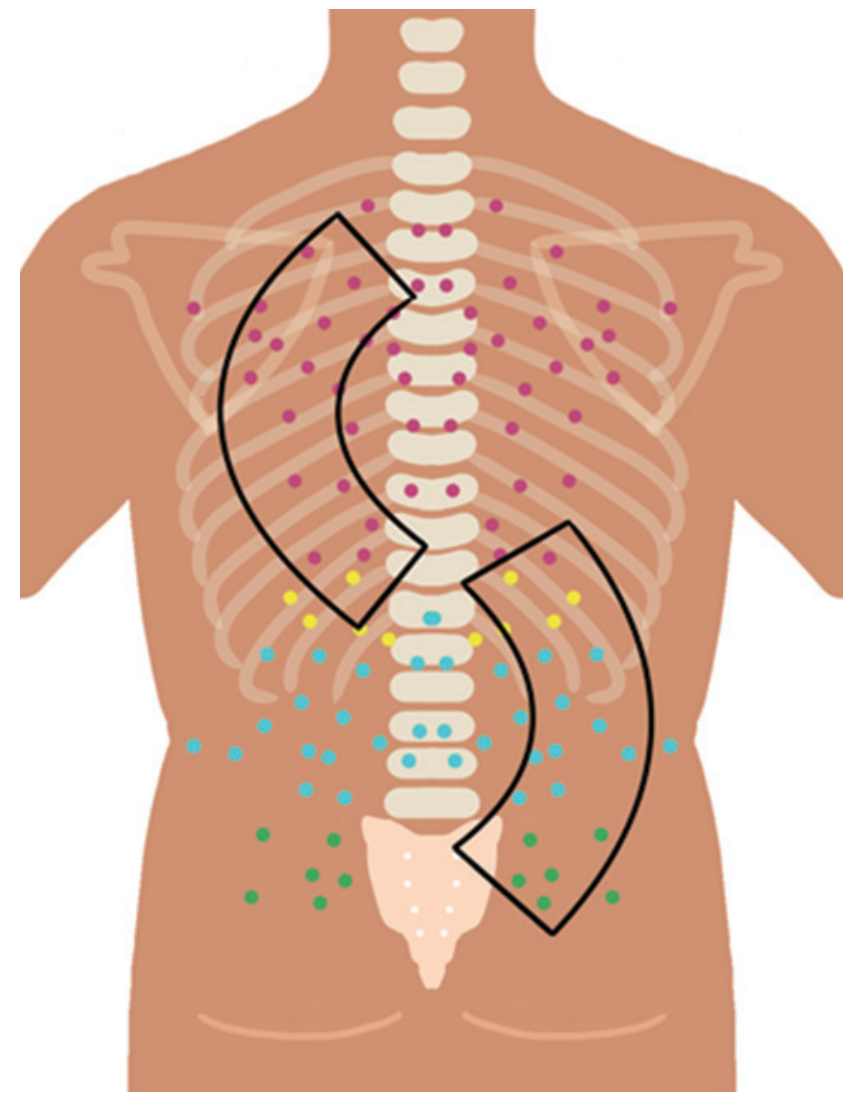

Fig. 1. Multi-perforator advancement flap. The keystone flap design safely includes thoracic and lumbar perforators along a longitudinal axis. Potential involvement of perforators depending on the level of the defect. Color code: purple, parascapular and scapular branches of the circumflex scapular artery superiorly, and dorsal intercostal arteries medially and inferiorly; yellow, intercostal arteries; blue, intercostal arteries, extensions of the superficial circumflex iliac artery laterally, and lumbar arteries inferiorly and medially; green, lumbar arteries.

cutaneous pedicled perforator flaps with a bilateral keystone design (keystone flaps). Medical records were analyzed retrospectively.

\section{Sample}

The sample consisted of neonatal patients, male or female, with myelomeningocele on whom a bilateral keystone flap was performed for skin closure between January 2018 and December 2020.

\section{Surgical technique}

Standard neural tube and meningeal closure was undertaken by the pediatric neurosurgery team. Proper debridement of damaged surrounding skin (usually thin and macerated) and hemostasis were performed, after which the actual size of the defect was established. The surgical lesion had an elliptical conformation with its long axis parallel to the line of the predominant 

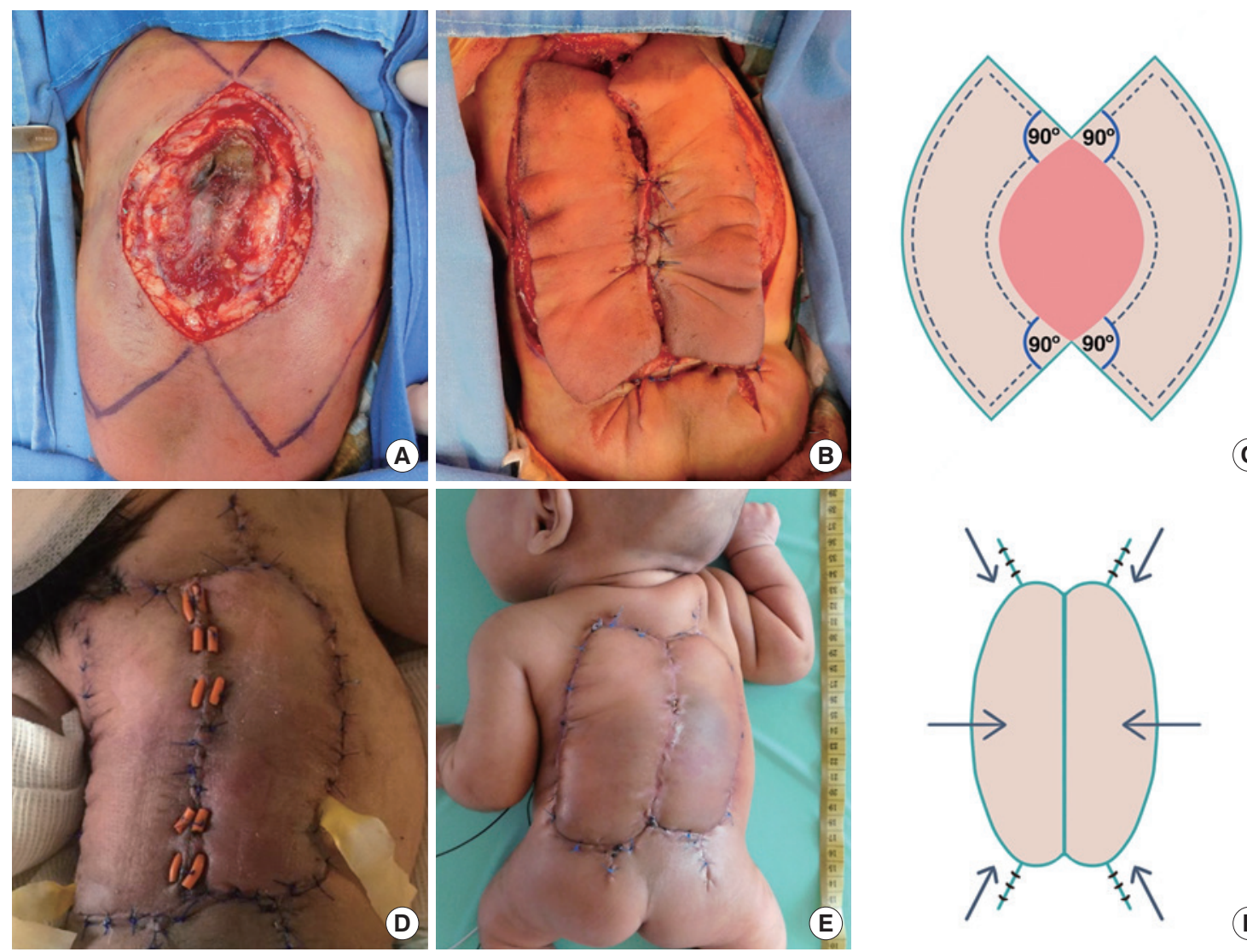

(C)

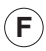

Fig. 2. Conventional double opposing keystone flap. (A) Patient with a skin defect after neural tube and meningeal closure (81 $\left.\mathrm{cm}^{2}\right)$. The surrounding skin was thin, macerated, and friable. For the keystone flap design, the defect diameter was marked in a 1:1 proportion bilaterally. Lines extended at right angles from the corners of the ellipse. When joining the opposite end, the flap was shaped on each side according to the width of the defect. (B) Blunt dissection enabled the preservation of perforators beneath the flap surface. A midline closure was done, at first covering the defect. Secondary defects at the edges were closed in a V-Y fashion, which relaxed the horizontal tension. Drains were placed and bolsters can be used to prevent the sutures from cutting through the skin. (D, E) Follow-up at postoperative days 7 and 21 , respectively: no necrosis or wound dehiscence was noted. (C, F) Diagrams of the design and result of bilateral keystone flaps (modified from Gaskill. Neurosurg Focus 2004;16:E3 [25]).

perforators $[13,14]$. The surface area of the flap was determined according to the size of the defect, and its diameter was marked in a 1:1 proportion bilaterally. A right angle was created at the vertex of the excision. From this angle, a line measuring the width of the defect was drawn and, with a curved line, was joined to the opposite line and angle to create the keystone design [14]. The dissection of the perforator vessels was performed using blunt-tip scissors in the subcutaneous fat plane. Progressive detachment of tissues and advancement to the midline were assessed continuously until tension-free closure was achieved in the midline. The outer tips of the flaps acted as V-Y advancement flaps that, when closed, created a relative redundancy in the central portion of the flap and relaxed the horizontal tension.

A minimum of two Penrose drains were placed subcutaneously in every patient. Simple inverted stitches made from absorbable monofilament were used for fat approximation. The skin was closed with simple stitches in the periphery made from nonabsorbable monofilament. Simple horizontal mattress sutures as well as bolsters were used intermittently in the midline (Fig. 2).

\section{Assessments}

We gathered data from each patient's clinical record and noted identifiable risk factors, gestational age, birth weight, the size and level of the defect, and complications detected during the follow-up.

\section{Ethical considerations}

The study was approved by the appropriate ethics review board and performed in accordance with the principles of the Declaration of Helsinki. All study participants (patients' parents or guardians) provided informed consent. Anonymity and confidentiality were preserved. 

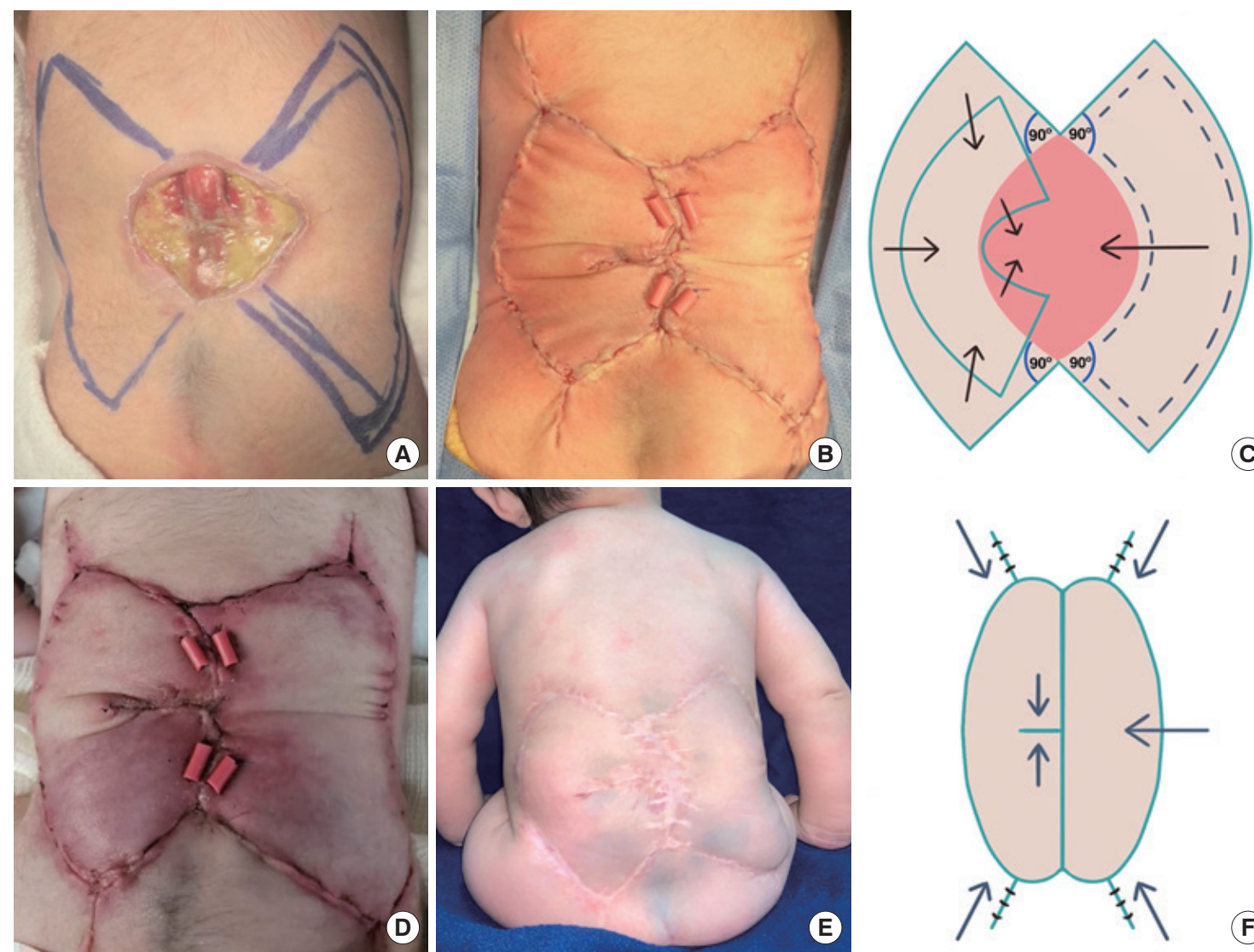

(C)

Fig. 3. Double keystone flap with an omega design. (A) Patient with a thoracolumbar myelomeningocele defect $\left(79 \mathrm{~cm}^{2}\right)$. (B) Immediate postoperative result shows a fish-mouth modification of the left keystone flap. Moderate bulging after inset may be present. (D) On postoperative day 5 , a congestive color change was observed that resolved within a few days without any additional measures. Notice flattening of the fishmouth configuration and proper wound healing. (E) Follow-up at 10 months of age. (C, F) Diagrams for the design and result of bilateral keystone flaps with an omega $(\Omega)$ or fish-mouth modification (modified from Gaskill. Neurosurg Focus 2004;16:E3 [25]).

Table 1. Myelomeningocele patients treated with a bilateral keystone flap

\begin{tabular}{lclcccccc}
\hline Patient & Sex & Risk factors & Gestation $(\mathrm{wk})$ & Age at surgery (day) & Birth weight $(\mathrm{g})$ & Defect size $\left(\mathrm{cm}^{2}\right)$ & Defect level & Complications \\
\hline 1 & M & Folic acid delayed & 38 & 1 & 2,800 & 56 & L1-L4 & Minimal seroma \\
2 & M & Folic acid delayed & 40 & 2 & 3,466 & 81 & T5-T10 & Peripheral dehiscence \\
3 & F & No folic acid & 39 & 1 & 2,340 & 64 & T10-L2 & None \\
4 & F & No folic acid & 36 & 2 & 1,950 & 49 & T4-T8 & None \\
5 & F & No folic acid & 39 & 1 & 2,600 & 100 & T3-T9 & None \\
6 & M & Folic acid delayed & 41.3 & 5 & 3,800 & 72 & T10-L3 & Peripheral dehiscence \\
7 & M & None & 41.6 & 8 & 3,270 & 79 & T10-L4 & Peripheral dehiscence \\
\hline
\end{tabular}

$\mathrm{M}$, male, F, female.

\section{RESULTS}

Our study analyzed data from seven patients with myelomeningocele in whom a bilateral keystone flap was performed for skin closure between January 2018 and December 2020, following neural tube and meningeal closure. Of the seven patients, three were female and four were male. The mean hospital stay was not prolonged by the surgical procedure. Patients were discharged after they had begun breastfeeding and all suture material had been removed. Five patients were treated using the conventional double opposing keystone flap (Behan type III) and two patients were treated via an omega-shaped modification (Fig. 3). The mean operative time was 61 minutes.

All patients were delivered via cesarean section. The average birth weight was $2,889 \mathrm{~g}$ (standard deviation, $656 \mathrm{~g}$ ). Surgery was performed before 48 hours of age in the majority of cases; however, surgery was delayed in some cases due to a late referral. The most commonly identified risk factor in our sample was null or delayed folic acid ingestion (Table 1).

The defects ranged in size from 49 to $100 \mathrm{~cm}^{2}$ (mean, 71.5 
$\mathrm{cm}^{2}$ ). The largest defect in our study also had the highest lesion level (at T3). Hydrocephalus was present in five out of seven patients. Surgical complications encountered during early followup were minimal. One patient had a minimal seroma treated with drainage and compression, and three patients suffered from areas of peripheral dehiscence that healed with conventional wound care procedures. There were no cases of midline or major dehiscence, flap loss, necrosis, surgical site infection, or cerebrospinal fluid leakage from the wounds, and no revision procedures were necessary.

All the flaps showed color changes in the early postoperative period and developed congestion and noticeable increases in flap volume around the second postoperative day. Loose padded bandages were applied along with local wound measures such as antibiotic ointment. If skin tension was present, some sutures were released.

\section{DISCUSSION}

Our aim was to study the role of keystone flaps for soft tissue closure in myelomeningocele patients and provide a rationale for its vascular supply. The optimal time for closure of open spina bifida and reconstruction of the adjacent soft tissues is immediately after birth. In our study, late referral from primary and secondary care hospitals was the main cause preventing timely surgery for soft tissue repair in some cases.

In our experience, most myelomeningoceles can be treated with direct closure by a neurosurgery team. In most other cases, closure is performed using a local transposition flap. It is only in very large defects that bilateral keystone flaps are used.

The rationale for this choice is the reliability of a flap with a clear anatomical foundation. The implicit preservation of perforators in the center of the flap design allows for a safer procedure when compared to random flaps that can undergo dehiscence or partial necrosis, transposition flaps that are usually limited to small defects [15], or flaps that, when large, require skin grafting for the donor site [8]. Although some authors have considered the keystone flap a salvage procedure following a failed primary closure, we use bilateral keystone flaps despite the size of the defect for the reconstruction of large defects in our practice [16]. The surface area of defects in our patients was greater than in most studies. In the study by Ozcelik et al. [6], the dimensions of the skin defects ranged from 24 to $48 \mathrm{~cm}^{2}$, whereas the largest defect in our study measured $100 \mathrm{~cm}^{2}$.

The keystone flap is designed as an advancement flap with a V-Y configuration at each end. It is oriented parallel to the longitudinal axis of the defect and results in an elliptical shape. Its particular value lies in its nourishment by multiple perforators preserved by a careful dissection technique. Since its original description in 2003 by Behan, it has become popular for the treatment of multiple kinds of soft tissue defects, traumatic or oncologic in nature, as well as for congenital defects such as myelomeningocele [13]. Typically, the dimensions of the flap should be 1:1 in proportion to the defect. Some additional essential considerations are the preservation of the perforators, circumferential incision of the deep fascia, and liberal undermining of the surrounding tissues to foster laxity and flexibility [17].

Major complication rates for myelomeningocele closure, regardless of the method, are between $8 \%$ and $20 \%$. Major complications include dehiscence in the midline with neural tissue exposure or an infection causing meningitis or ventriculitis. Minor complications (seroma or peripheral and partial dehiscence) occur in around 20\% of cases [18]. Primary closure and transposition flaps are the procedures with the highest complication rates. Some cases of wound necrosis and midline dehiscence even require secondary procedures such as rotation flaps or skin grafts [15]. There were no major complications in any patients in our study. Cases of minor dehiscence were treated with conservative measures.

With respect to surgical planning, the tissue used for reconstruction must be located close to the defect. Although vascular microsurgical procedures have been described anecdotally in neonates, these have mainly been revascularizations [19]. In the exceptional case of a free flap, postoperative care is difficult. For example, heparinization is precluded due to the risk of an unrecognized intracranial bleed in neonates. Furthermore, the skills of the microsurgical team must be extraordinary for success [20].

The tissues adjacent to the defect are vascularized by the same arterial and venous systems regardless of the reconstructive method chosen. Thus, the difference between a transposition flap and a keystone flap, as both are based on thoracic or lumbar perforators, is the grade of complexity and the advantage of avoiding random blood flow in the latter.

The identification of perforator vessels in neonates is very difficult, although possible, with the use of Doppler ultrasonography [21]. Our results show that anatomically based preoperative planning yields reproducible results in most cases without the need for extra procedures. Additionally, it should be pointed out that vascular adaptation occurs in the first postoperative days with marked congestion in the flap that subsides after 72 hours. Minimal and easy-to-heal peripheral dehiscence can also be expected. These results should not alarm a surgeon. We believe that these considerations regarding the blood supply of the flap from an anatomical standpoint and the clinical manifestations 
of vascular changes are an original perspective that has not been discussed extensively in other reports.

A similar study to ours was published by Formentin et al. [22]. In their report, some patients underwent intrauterine repair with insufficient closure of the soft-tissue defect, thus requiring a keystone flap as a secondary procedure after birth. All defects were closed using conventional bilateral keystone flaps. The authors' discussion of the use of random perforators for harvesting the flap is a particularly notable issue. As we mentioned previously, other studies have demonstrated the vascular supply is provided by perforators of the dorsal intercostal and lumbar systems [8-10]. However, these papers did not report identifiable risk factors for myelomeningocele. In contrast, our study identified that almost the whole sample had null or delayed ingestion of folic acid, starting at the mid-second trimester of pregnancy. While folic acid consumption does not modify biochemical and hematological parameters such as hemoglobin levels and the rate of anemia, it is routinely advised from the first trimester of pregnancy, or even 1 month before, to prevent neural tube defects [3].

We must emphasize that, in our opinion, keystone flaps are a very useful option for defect closure in myelomeningocele, especially if the surgeon has previously used this kind of flap for other, perhaps less critical, body regions. The advantages of this flap are a relatively short operative time compared to free flaps and its suitability for patients who cannot undergo prolonged complex reconstructive procedures since the perforators do not need to be surgically identified [11]. Furthermore, there are many available modifications. One such modification is the omega-type keystone flap, also known as a fish-mouth variant, where the central portion advances toward the defect due to rotation and advancement of the lateral segments of the flap [12].

A further advantage is the possibility of sensation, since it has been reported that some keynote flaps have resulted in postoperative sensitivity despite transection of the superficial cutaneous nerves [12].

Some limitations of our study are its retrospective and observational design, as well as the small sample size and lack of a control group. Nevertheless, we acknowledge that in the realm of reconstructive plastic surgery, the treatment of complex defects in prospective, controlled, and randomized trials are difficult to achieve.

Taking into account the variety of reconstructive procedures for the treatment of defects such as those described in this paper, we believe that the keystone flap enriches the armamentarium of reconstructive plastic surgeons with the clear advantage of having a logical and uncomplicated design in the already challenging scenario of myelomeningocele defects [23]. We empha- size the importance of follow-up to establish the advantages of one technique above others in the long term. For example, at the moment, no surgical procedure has been shown to decrease the rate of spinal cord tethering $(15 \%-20 \%)$. This is a very relevant issue that should be clarified in the future and may require prospective studies [24,25].

\section{NOTES}

\section{Conflict of interest}

No potential conflict of interest relevant to this article was reported.

\section{Ethical approval}

The study was approved by the Institutional Review Board of Hospital Infantil de México (IRB No. HIM-2020-052) and performed in accordance with the principles of the Declaration of Helsinki. Written informed consent was obtained.

\section{Patient consent}

The patient's guardian provided written informed consent for the publication and the use of the patient's images.

\section{Author contribution}

Conception and design: BH Kushida-Contreras, MA GaxiolaGarcía. Acquisition of data, analysis and interpretation of data: BH Kushida-Contreras, MA Gaxiola-García. Drafting, critical revision, and final approval of the version to be published: $\mathrm{BH}$ Kushida-Contreras, MA Gaxiola-García.

\section{ORCID}

Beatriz Hatsue Kushida-Contreras

https://orcid.org/0000-0003-3027-3707

Miguel Angel Gaxiola-García

https://orcid.org/0000-0003-3431-5150

\section{REFERENCES}

1. Mitchell LE, Adzick NS, Melchionne J, et al. Spina bifida. Lancet 2004;364:1885-95.

2. Copp AJ, Adzick NS, Chitty LS, et al. Spina bifida. Nat Rev Dis Primers 2015;1:15007.

3. Chitayat D, Matsui D, Amitai Y, et al. Folic acid supplementation for pregnant women and those planning pregnancy: 2015 update. J Clin Pharmacol 2016;56:170-5.

4. Sharrard WJ, Zachary RB, Lorber J. Survival and paralysis in open myelomeningocele with special reference to the time 
of repair of the spinal lesion. Dev Med Child Neurol 1967; Suppl 13:35-50.

5. Adzick NS, Thom EA, Spong CY, et al. A randomized trial of prenatal versus postnatal repair of myelomeningocele. $\mathrm{N}$ Engl J Med 2011;364:993-1004.

6. Ozcelik D, Yildiz KH, Is M, et al. Soft tissue closure and plastic surgical aspects of large dorsal myelomeningocele defects (review of techniques). Neurosurg Rev 2005;28:218-25.

7. Duffy FJ Jr, Weprin BE, Swift DM. A new approach to closure of large lumbosacral myelomeningoceles: the superior gluteal artery perforator flap. Plast Reconstr Surg 2004;114:1864-8.

8. Iacobucci JJ, Marks MW, Argenta LC. Anatomic studies and clinical experience with fasciocutaneous flap closure of large myelomeningoceles. Plast Reconstr Surg 1996;97:1400-8.

9. Kiil BJ, Rozen WM, Pan WR, et al. The lumbar artery perforators: a cadaveric and clinical anatomical study. Plast Reconstr Surg 2009;123:1229-38.

10. Isik D, Tekes L, Eseoglu M, et al. Closure of large myelomeningocele defects using dorsal intercostal artery perforator flap. Ann Plast Surg 2011;67:159-63.

11. Abraham JT, Saint-Cyr M. Keystone and pedicle perforator flaps in reconstructive surgery: new modifications and applications. Clin Plast Surg 2017;44:385-402.

12. Gomez OJ, Baron OI, Penarredonda ML. Keystone flap: overcoming paradigms. Plast Reconstr Surg Glob Open 2019;7: e2126.

13. Mohan AT, Rammos CK, Akhavan AA, et al. Evolving concepts of keystone perforator island flaps (KPIF): principles of perforator anatomy, design modifications, and extended clinical applications. Plast Reconstr Surg 2016;137:1909-20.

14. Behan FC. The keystone design perforator island flap in reconstructive surgery. ANZJ Surg 2003;73:112-20.
15. Shim JH, Hwang NH, Yoon ES, et al. Closure of myelomeningocele defects using a Limberg flap or direct repair. Arch Plast Surg 2016;43:26-31.

16. Gomez O, Barrera C. Keystone flap: a safe coverage option in the handling of salvage for myelomeningocele. Childs Nerv Syst 2020;36:2765-74.

17. Mohan AT, Sur YJ, Zhu L, et al. The concepts of propeller, perforator, keystone, and other local flaps and their role in the evolution of reconstruction. Plast Reconstr Surg 2016; 138:710e-729e.

18. Gutman MJ, Goldschlager T, Fahardieh RD, et al. Keystone design perforator island flap for closure of myelomeningocele. Childs Nerv Syst 2011;27:1459-63.

19. Lees VC. Successful revascularization of subtotal amputation of a digit in a neonate. J Hand Surg Am 1999;24:812-5.

20. Son J, Medalie DA. Free-flap treatment of congenital pressure necrosis of the forearm in the neonate. J Reconstr Microsurg Open 2016;1:29-31.

21. Imaizumi A. Duplex ultrasonography-assisted freestyle pedicled perforator flaps for the repair of myelomeningocele defects. Ann Plast Surg 2018;80:539-45.

22. Formentin C, de Andrade EJ, Matias LG, et al. Using the keystone design perforator island flap in large myelomeningocele closure. Neurosurg Focus 2019;47:E19.

23. Lee HG, Lim SY, Kim YK, et al. Keystone design perforator island flaps for coverage of non-oncological periarticular defects surrounded by the zone of injury. J Int Med Res 2020; 48:1-14.

24. Woodhouse CR. Myelomeningocele: neglected aspects. Pediatr Nephrol 2008;23:1223-31.

25. Gaskill SJ. Primary closure of open myelomeningocele. Neurosurg Focus 2004;16:E3. 